\title{
Pandemic's impact on inguinal hernia management in infants
}

\author{
C. de la Sen Maldonado, N. Albertos Mira-Marcellí, V. Díaz Díaz, M.G. Toro Rodríguez, J. Gonzálvez Piñera \\ Pediatric Surgery Department. Alicante General University Hospital. Alicante (Spain).
}

\begin{abstract}
Introduction. The SARS-CoV-2 pandemic brought about a reduction in surgical activity. The objective of this work was to analyze its impact on inguinal hernia morbidity.

Materials and methods. A retrospective study of cases and controls was carried out. Patients under 18 months of age undergoing inguinal hernia surgery from January 1, 2019 to August 31, 2020 were included. They were divided into two groups: patients undergoing surgery before (group A) or after (group D) the state of alarm was declared in Spain. Primary variables: episodes of incarceration and postoperative complications. Secondary variable: urgent or scheduled surgery. Demographic variables: sex, gestational age (GA), previous pathologies, age at diagnosis (AD), and age at surgery (AS) (months).

Results. 64 patients were included -43 in group A and 21 in group D. In group A, median GA was $37+3,90.5 \%$ of patients were male, median $\mathrm{AD}$ was 2.33 , and median $\mathrm{AS}$ was 3.27. In group $\mathrm{D}$, median GA was $31+2,72.1 \%$ of patients were male, median $\mathrm{AD}$ was 3 , and median AS was 3.63. There were no statistically significant differences. However, differences in terms of previous pathologies were significant $(16.3 \%$ for Group A vs. $38.1 \%$ for group D) $(\mathrm{p}=$ 0.05 ). Regarding the primary variable, $25.6 \%$ of patients in group A had incarcerations vs. $33.3 \%$ of patients in group D ( $\mathrm{p}=0.51)$, whereas $9.3 \%$ of patients in group A had postoperative morbidity $v s$. $14.3 \%$ of patients in group D $(\mathrm{p}=0.41)$. Regarding the secondary variable, $88.4 \%$ of surgeries in group A were scheduled vs. $90.5 \%$ of surgeries in group $\mathrm{D}(\mathrm{p}=0.583)$.

Conclusion. In spite of reduced surgical activity, inguinal hernia morbidity did not surge in our environment. An increase in patients with previous pathologies was noted, which means severe patients should be prioritized.
\end{abstract}

KeY Words: Inguinal childhood hernia; General surgery; Pediatrics; SARS-CoV-2.

DOI: $10.54847 /$ cp.2022.01.12

Corresponding author: Dr. Carlos de la Sen Maldonado.

E-mail address: csenmal@gmail.com

This work was accepted as an oral presentation at the 59th Congress of the Spanish Pediatric Surgery Society.

Date of submission: May 2021

Date of acceptance: November 2021
IMPACTO DE LA PANDEMIA EN EL MANEJO DE LA HERNIA INGUINAL EN LACTANTES

\section{RESUMEN}

Introducción. La pandemia del SARS-CoV-2 supuso una reducción de las jornadas quirúrgicas. Analizamos el efecto en la morbilidad de la hernia inguinal.

Material y método. Estudio retrospectivo de casos y controles. Incluimos menores de 18 meses intervenidos de hernia inguinal desde 01/01/2019 hasta 31/08/2020, divididos en 2 grupos: intervenidos antes (grupo A) o después (grupo D) de la declaración del estado de alarma. Variables principales: episodios de incarceraciones y complicaciones postoperatorias. Variable secundaria: intervención urgente o programada. Variables poblacionales: sexo, edad gestacional (EG), patología previa, edad al diagnóstico(ED) y a la intervención (EI) (meses).

Resultados. Incluimos 64 pacientes, 43 grupo A y 21 grupo D. En el grupo A la mediana de EG fue $37+3$, el 90,5\% fueron varones, la mediana ED fue 2,33 y EI 3,27. En el grupo B la mediana de EG fue $31+2$, el 72,1\% fueron varones, la mediana ED fue 3 y EI 3,63 . No hubo diferencias estadísticamente significativas. Si fueron significativas las diferencias en patología previa $16,3 \%$ A y $38,1 \%$ $\mathrm{D}(\mathrm{p}=0,05)$. Sobre la variable principal: $25,6 \%$ del A sufrieron incarceraciones frente a $33,3 \%$ del D $(\mathrm{p}=0,51)$ y un $9,3 \%$ tuvieron morbilidad postoperatoria en A frente a $14,3 \%$ en D $(p=0,41)$. Respecto a la variable secundaria un $88,4 \%$ se realizaron de forma programada en el grupo A y un 90,5\% en el grupo D $(\mathrm{p}=0,583)$.

Conclusión. Pese a la reducción de jornadas quirúrgicas no ha aumentado la morbilidad de la hernia inguinal en nuestro medio. Hemos observado un aumento de pacientes con patología previa, implicando la priorización de los pacientes más graves.

Palabras Clave: Hernia inguinal infantil; Cirugía pediátrica; SARS-CoV-2.

\section{INTRODUCTION}

Inguinal hernia is one of the most frequent pathologies in pediatric surgery, with a prevalence of approximately $5 \%$ in male patients. The highest incidence rates are found in children under 1 year of age, and incarceration risk is also greater in this age group ${ }^{(1)}$. Complication risk factors 
Table I. Quantitative demographic variables and statistical significance.

\begin{tabular}{|c|c|c|c|c|c|c|c|}
\hline \multirow{3}{*}{ GA (weeks) } & \multicolumn{3}{|c|}{ Group A } & \multicolumn{3}{|c|}{ Group D } & \multirow[b]{2}{*}{$p$} \\
\hline & Median & \multicolumn{2}{|c|}{$95 \%$ confidence interval } & Median & \multicolumn{2}{|c|}{$95 \%$ confidence interval } & \\
\hline & 37.30 & 36.00 & 38.00 & 31.10 & 29.40 & 37.00 & 0.073 \\
\hline Age at diagnosis (months) & 2.33 & 2.16 & 2.96 & 2.96 & 1.40 & 3.96 & 0.902 \\
\hline Age at surgery (months) & 3.28 & 2.80 & 4.23 & 3.58 & 2.60 & 4.83 & 0.374 \\
\hline
\end{tabular}

in inguinal hernia are well-known. However, time from diagnosis to surgery is an independent incarceration risk factor $^{(2)}$, with the resulting increase in morbidity.

The SARS-CoV-2 pandemic represented an unprecedented challenge for the Spanish healthcare system, not only in terms of assisting COVID-19 patients, but also patients with other pathologies in such a peculiar health and social context, with the restrictions enforced by the state of alarm. The whole healthcare activity had to change, with scheduled surgeries being reduced, and in-person medical consultations being limited. One of the main concerns for healthcare professionals who assisted the pediatric population in this period is how potential diagnosis and treatment delays may have impacted our patients.

Therefore, the objective of this work was to assess whether healthcare reorganization as a result of the SARS$\mathrm{CoV}-2$ pandemic caused morbidity in infants undergoing inguinal hernia surgery in our environment to increase.

\section{MATERIALS AND METHODS}

An observational, retrospective study of cases and controls was carried out by reviewing the clinical records of all patients under 18 months of age undergoing inguinal hernia repair at the pediatric surgery department from January 1, 2019 to August 31, 2020. Patients were divided into 2 groups according to whether they had undergone surgery before (group A) or after (group D) the state of alarm was declared in Spain on March 14, 2020(3), when all scheduled surgeries in our environment were cancelled.

Patients with an incomplete clinical record not allowing all clinical data required for the study to be retrieved were excluded.

Demographic variables collected included sex, gestational age (GA) (weeks), previous pathologies (major heart, respiratory, or neurological disease), age at diagnosis (AD) (months), and age at surgery (AS) (months).

Primary outcome variables were preoperative morbidity (episodes of incarceration before surgery) and postoperative morbidity (postoperative complications), both as qualitative variables. The secondary variable analyzed whether surgery had been urgent or scheduled.
Data collection was carried out by reviewing electronic clinical records. Access to records from all patients diagnosed with inguinal hernia (K40 code in CIE-10) or having undergone inguinal hernia repair (codes 0YQ50ZZ, 0YQ60ZZ, and 0YQA0ZZ) in the study period was requested to the clinical documentation department. The relevant form was filled out using the Microsoft Office Access $^{\ominus}$ software.

Hypothesis testing study was performed using the IBM SPSS statistics v25 ${ }^{\circ}$ software. Statistical tests used included chi-square test or Fisher's exact test for qualitative variables, and Student's t-test or Mann-Whitney U test for quantitative variables. For risk measurement purposes, odds ratio was calculated with a $95 \%$ confidence interval. Statistical significance was established at $\mathrm{p}<0.05$.

\section{RESULTS}

68 patients met inclusion criteria. 4 patients were excluded because their clinical record was incomplete. Of the 64 remaining patients, 43 had undergone surgery before the state of alarm was declared in Spain and were allocated to group A, whereas 21 had undergone surgery after the state of alarm was declared in Spain and were allocated to group D.

In group A, $90.5 \%$ of patients were male, $16.3 \%$ of patients had previous pathologies, median gestational age was 37.3 weeks, median age at diagnosis was 2.3 months, and median age at surgery was 3.3 months.

In group D, $72.1 \%$ of patients were male, $38.09 \%$ of patients had previous pathologies, median gestational age was 31.2 weeks, median age at diagnosis was 2.9 months, and median age at surgery was 3.58 months.

Table I features the demographic characteristics of both groups. Differences were not statistically significant, except for patients with previous concomitant pathologies $(\mathrm{p}=0.035)$.

Regarding the primary outcome variables:

- $25.6 \%$ of patients in group A had at least 1 episode of incarceration vs. 33.3\% of patients in group D. Odds Ratio (OR) was 1.61 (95\% confidence interval $(\mathrm{CI})$ : 0.514-5.07), without statistical significance $(\mathrm{p}=0.51)$. 
Table II. Preoperative morbidity (primary outcome variable): significance and risk measurement.

\begin{tabular}{lcc} 
& Group A & Group D \\
\hline Incarceration & 11 & 7 \\
\hline No incarceration & 32 & 14 \\
\hline $\mathrm{p}=0.51$ & OR $=1.61(95 \%$ CI: $0.514-5.07)$
\end{tabular}

- $9.3 \%$ of patients in group A had postoperative complications vs. $14.3 \%$ of patients in group D. OR was 1.625 (95\% CI: 0.329-8.030), without statistical significance $(\mathrm{p}=0.41)$.

Results are featured in Tables II and III.

Regarding the secondary variable, $11.6 \%$ of surgeries in group A were urgent $v s .9 .5 \%$ of surgeries in group D, without statistical significance $(\mathrm{p}=0.583)$.

\section{DISCUSSION AND CONCLUSIONS}

Numerous studies analyzing the impact of the SARSCoV-2 pandemic on health, both as a result of mortality rates in the most fragile population and the increase in morbidity and mortality of severe non-COVID pathologies owing to delayed healthcare assistance, are starting to $\operatorname{arise}^{(4.5)}$.

Surgically speaking, many studies have shown a reduction in the number of urgent procedures during the pandemic $^{(6-9)}$. Some studies have also revealed an increase in time to treatment as a result of delayed diagnosis, with the resulting increment in morbidity and mortality rates ${ }^{(9)}$.

According to a May 2020 study, "In the peak 12 weeks of the COVID-19 pandemic, 28,404,603 surgeries were cancelled or postponed. A mean of 45 weeks at a $120 \%$ workload would be required to make up lost ground."(10). This shows that the impact of the SARS-CoV-2 pandemic on healthcare assistance will still be present for a long time.

Multiple articles demonstrate that incarceration risk increases with delayed diagnosis ${ }^{(1,11-14)}$. Zamakhshary M. et al. observed that the risk of developing an episode of incarceration was two-fold when time from diagnosis to surgery exceeded 14 days ${ }^{(2)}$.

At the time this article was written, there were no instances of pediatric surgery studies analyzing inguinal hernia morbidity in children during pandemic times in the literature.

However, three articles on adult patients were found. Lima DL et al.'s(15) showed a statistically significant decrease in urgent surgeries and hernia-related consultations during pandemic times.

In our sample, patients undergoing surgery during the pandemic had a higher proportion of previous pathologies,
Table III. Postoperative morbidity (primary outcome variable): significance and risk measurement.

\begin{tabular}{lcc} 
& Group A & Group D \\
\hline Postoperative morbidity & 4 & 3 \\
\hline No postoperative morbidity & 39 & 118 \\
\hline $\mathrm{p}=0.41$ & $\mathrm{OR}=1.625(95 \%$ CI: $0.329-8.030)$
\end{tabular}

and they were also younger. We believe this is a result of surgical activity limitation, which made us prioritize more complex patients in order to reduce complication risks as much as possible.

It could also be explained by the fact the number of complex patients did not diminish, since they are usually referred from neonatology units, which did not experience such an important decline in activity. On the contrary, the amount of patients with milder conditions, who are usually referred from primary care institutions, could have decreased as a result of pandemic restrictions in walk-in clinics.

A slight increase in age at diagnosis and age at surgery was also noted. This is consistent with the fact patients are diagnosed later, which means surgery also takes place at a more advanced age.

An increase in perioperative morbidity was detected, namely with an increment in incarceration episodes. This is consistent with the fact delayed diagnosis and treatment cause the risk of incarceration and postoperative complications in inguinal hernia to surge $e^{(1,2)}$. However, the differences observed were not significant in the hypothesis testing study. The limited sample size of our study could be accountable for this, since differences may not be large enough to be detected, or simply may not exist.

No increase in the proportion of urgent surgeries was noted. In our study, the only indication for urgent surgery was the impossibility of reducing incarceration through Taxis maneuvers. Given that the proportion of hernias undergoing urgent surgery did not surge, we assume hernia reduction success rates have remained unchanged.

Regarding potential study limitations and biases, it should be highlighted that our sample was quite small, which means great clinical differences are required for them to be statistically significant. Studies with a larger patient cohort, and especially multi-center studies, are therefore required to draw conclusions based on greater evidence.

In addition, the fact this was a retrospective study adds some potential biases, such as losses of patients as a result of not being adequately coded in their electronic clinical record. An even if coding is adequate, clinical records may be incomplete, which prevents information from being gathered from the variables. 
It should also be considered that group D had a shorter follow-up time, which means long-term effects might not have been observed.

In conclusion, in spite of the reduction in surgical activity and external consultation visits the pandemic brought about, no increase in preoperative or postoperative morbidity in patients undergoing inguinal hernia surgery was noted. Additionally, in this time period, patients had a greater proportion of previous pathologies, and they were also younger, which means there was a higher risk of complications. This made us prioritize more complex patients as the number of patients eligible for surgery was limited.

\section{REFERENCES}

1. Zamakhshary M, To T, Guan J, Langer JC, et al. Risk of incarceration of inguinal hernia among infants and young children awaiting elective surgery. CMAJ. 2008; 179: 1001-5.

2. Sulkowski JP, Cooper JN, Duggan EM, et al. Does timing of neonatal inguinal hernia repair affect outcomes? J Pediatr Surg. 2015; 50: 171-6.

3. Real Decreto 463/2020, de 14 de marzo, por el que se declara el estado de alarma para la gestión de la situación de crisis sanitaria ocasionada por el COVID-19. Ref. BOE-A-2020-3692.

4. Blecker S, Jones SA, Petrilli CM, et al. Hospitalizations for chronic disease and acute conditions in the time of COVID-19. JAMA Intern Med. 2021; 181(2): 269-71.

5. Bhambhvani HP, Rodrigues AJ, Yu JS, Carr JB II, Hayden Gephart M. Hospital volumes of 5 medical emergencies in the COVID-19 pandemic in 2 US medical centers.JAMA Intern Med. 2021; 181(2): 272-4.

6. Gupta R, Gupta J, Ammar H. Impact of COVID-19 on the outcomes of gastrointestinal surgery. Clin J Gastroenterol [Internet].
2021; 14: 932-46. Available from: https://doi.org/10.1007/ s12328-021-01424-4

7. Cano-Valderrama O, Morales X, Ferrigni CJ. Reduction in emergency surgery activity during COVID-19 pandemic in three Spanish hospitals. Br J Surg. 2020; 107(8): e239.

8. Patriti A, Eugeni E, Guerra F. What happened to surgical emergencies in the era of COVID-19 outbreak? Considerations of surgeons working in an Italian COVID-19 zone. Updates Surg. 2020; 72(2): 309-10.

9. Cano-Valderrama O, Morales X, Ferrigni CJ, et al. Acute care surgery during the COVID-19 pandemic in Spain: changes in volume, causes and complications. A multicentre retrospective cohort study. Int J Surg. 2020; 80: 157-61.

10. COVIDSurg Collaborative. Elective surgery cancellations due to the COVID-19 pandemic: global predictive modelling to inform surgical recovery plans. Br J Surg. 2020; 107(11): 1440-9.

11. Sulkowski JP, Cooper JN, Duggan EM, Balci O, Anandalwar SP, Blakely ML, et al. Does timing of neonatal inguinal hernia repair affect outcomes? J Pediatr Surg. 2015; 50(1): 171-6.

12. Wang KS, Papile LA, Baley JE, Benitz W, Cummings J, Carlo WA, et al. Assessment and management of inguinal hernia in infants. Pediatrics. 2012; 130(4): 768-73.

13. Espósito C, Escolino M, Turrà F, Roberti A, Cerulo M, Farina A, et al. Current concepts in the management of inguinal hernia and hydrocele in pediatric patients in laparoscopic era. Semin Pediatr Surg [Internet]. 2016; 25(4): 232-40. Available from: http://dx.doi.org/10.1053/j.sempedsurg.2016.05.006

14. Duggan EM, Patel VP, Blakely ML. Inguinal hernia repair in premature infants: More questions than answers. Arch Dis Child Fetal Neonatal Ed. 2015; 100(4): F286-8.

15. Lima DL, Pereira X, dos Santos DC, Camacho D, Malcher F. Where are the hernias? A paradoxical decrease in emergency hernia surgery during COVID-19 pandemic. Hernia. 2020; 24(5): 1141-2. 